general relativity allows for the possible and practical realization of time travel. This heightened interest followed the 1988 paper published in Physical Review Letters by Thorne and his colleagues on the physics of wormholes, shortcuts through space and perhaps time. The paper was inspired by a question Carl Sagan posed to Thorne when writing his science-fiction novel Contact.

The discussion of time travel in a mainstream science publication attracted media attention and piqued interest in the scientific community. It also encouraged a lot of fanciful speculation by scientists about ideas on the very edges of respectability. And it motivated the writing of numerous popular books.

Since the mid-1990s, most concrete results regarding the possibility of time travel have been negative. The few outstanding issues ended up mired in quantum gravity, which remains ill-defined and elusive. As a result, interest in this issue in the physics community has subsided somewhat.

Toomey remains enamoured with the philosophical and literary possibilities of time travel, so is less critical of some dubious proposals than he might be. He nevertheless provides a largely accurate rendering of timetravel science with all its twists and turns, errors and dead ends. This is sometimes frustrating: it is tough to labour through detailed discus-

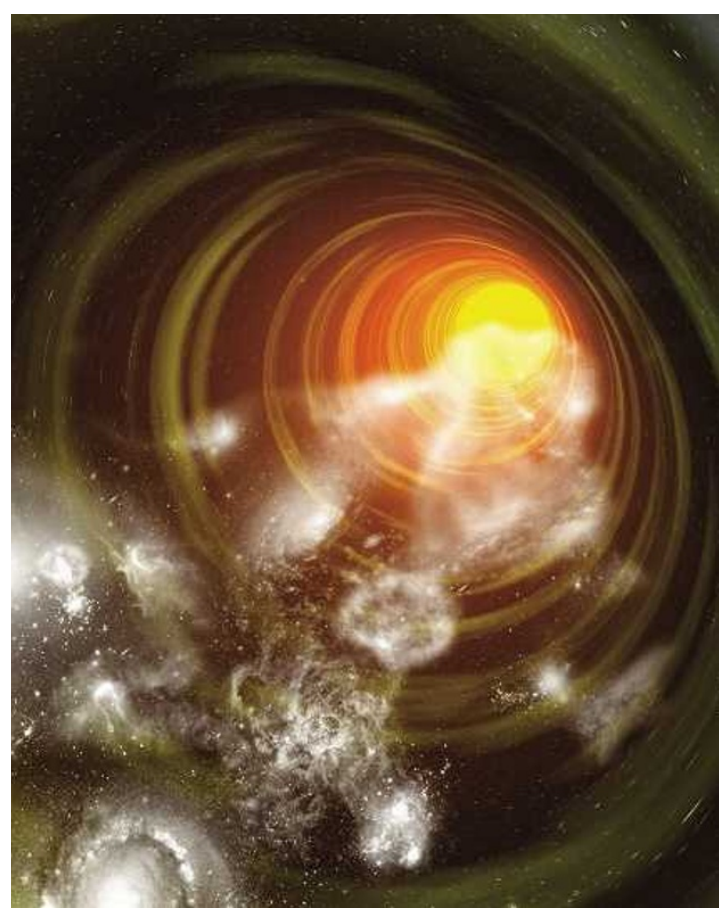

The physics of wormholes: are there shortcuts through time?

sions of complex ideas that Toomey eventually correctly reveals to have proved fruitless. But it is also refreshing: popular books too often present research as a logical narrative that bears little relation.

Errors, as might be expected from someone writing outside his field, have crept in. Early discussions of physics, including special and general relativity, are quite clear. Later explanations of modern topics, such as inflation, are more uneven. A grating mistake is Toomey's statement that the Planck length is a million times smaller than the size of a proton. It is actually closer to a million million million times smaller. We regularly investigate regions a million times smaller than a proton with large-particle accelerators: it is the vast chasm between even these minute sizes and the Planck length that makes probing quantum gravity so difficult.

Aside from such gaffs, The New Time Travelers is sound and informed. If readers leave this book feeling unsatisfied, Toomey may have done them a service. He captures the nature of the scientific process - that one never knows where fundamental research will lead, that most of it doesn't result in ground-breaking developments, and that even negative results can prove enlightening. It is sometimes difficult for us to be honest about these facets when popularizing our work. That an 'outsider' has captured this is impressive, and useful.

Lawrence M. Krauss is director of the Center for Education and Research in Cosmology and Astrophysics at Case Western Reserve University, Cleveland, Ohio 44106, USA. He is author of Hiding in the Mirror: The Quest for Alternate Realities, from Plato to String Theory.

\title{
Scientists on film
}

\section{Hollywood Science: Movies, Science, and the End of the World \\ by Sidney Perkowitz \\ Columbia University Press: 2007. 256 pp. $\$ 24.95$}

\section{Emma Marris}

Science-fiction films are often called to account by scientists - for their inaccuracies and for skipping over the years of gruelling effort behind discoveries. But film is not particularly interested in reality. It is obsessed with unreality, which, after all, is why we go to the movies. We get reality at home. Hollywood Science reveals, perhaps inadvertently, what scientists owe to film: a kindling of interest in scientific concepts that shadows the audience as they leave the cinema.

In film, science and scientists act as a magic key to the unknown. They take us into realms where people and animals mingle in the same individual, where heads live apart from bodies, where aliens and robots and clones wear shiny jumpsuits and talk to their watches and make love. In the cheesy 1994 film Stargate, a hammy James Spader plays an egyptologist who saunters into a military industrial complex and does his science thing, which enables guys with guns to walk through a door into another world. In films involving an atomic bomb, scientists turn a key that leads to a bleak but fascinating future. Science provides new modes of transportation and new destinations: time machines to the future and rockets to the stars.

Yes, researchers may cringe at some of cinema's favourite lab-coated characters - the effeminate egghead who wants to negotiate with murderous aliens, or those government jerks in hazmat suits who wanted to carve up ET. But the important thing, perhaps, is that science and scientists continue to be used to expand the world of film in imaginative ways. These themes reveal that, despite its anti-science spasms, the culture at large believes that science is a means to go places, see things and know more, for good or ill.

Over the years, scientists have complained that they are not in fact megalomaniac geniuses with delusions of godhead that prompt their hair to stand on end, like Victor Frankenstein, or Dr Rotwang in Metropolis. This earnest refutation does not do much to dispel another scientific stereotype: that of the humourless pedants immune to the communal pleasures

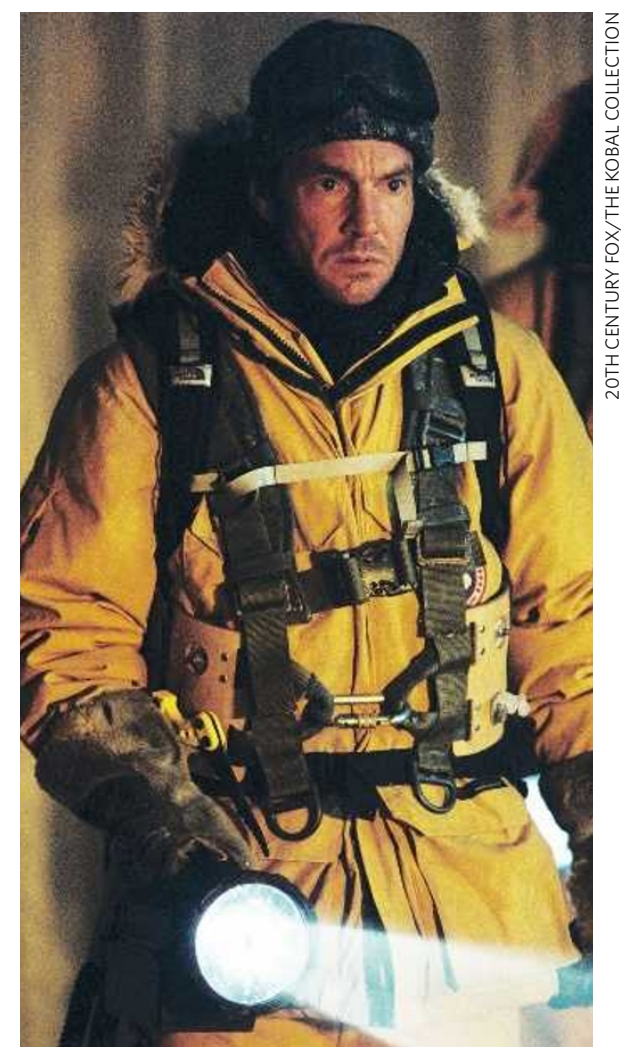

Dennis Quaid, with stern expression, as a scientist in The Day after Tomorrow in 2004. 
of humanity. Dennis Quaid plays one such caricature in the climate-change-themed The Day After Tomorrow, in which he maintains a grimly furrowed brow, perhaps to detract from the scientific howlers in the film.

Sidney Perkowitz, a physicist at Emory University in the United States, keeps up the tradition of examining the stock cinematic geeks. He says that the stereotypes are not entirely without basis, observing that, on average, one-third of the men at scientific conferences have facial hair and half of both sexes wear glasses. Scientists can be arrogant, he maintains, and "real scientists aren't usually the brightest sparks in the room - often interestingly quirky, yes, but not necessarily loads of fun."

Perkowitz's book is an affectionate examination of dozens of science-fiction films. If you don't want endings spoiled, avoid this book.
Detailed plot summaries alternate with short, layman-level explanations of the research behind such staples as asteroids hitting Earth, computers taking over, atomic holocausts and alien invasions.

It is not clear whether Perkowitz has written this book for teenagers or whether his exuberance transports him into a state of child-like rapture, but what comes across is a slightly naïve enthusiasm. This may speak to the difficulty of switching from science to cultural criticism.

He saves his scorn for just a few movies. One, The Core (a 2003 flick in which the Earth's core stops rotating and has to be restarted by a team drilling down to the Earth's centre to set off nuclear explosions), seems to have been made deliberately to annoy scientists. Another, What the $\# \$^{*}$ ! Do We $(K)$ now! , is actually a promo- tional film for an affluent US cult, led by a woman in Tacoma, Washington, who 'channels' a 35,000-year-old warrior. Pretty much everything else, Perkowitz likes. Evil scientists, wimpy scientists, boring scientists - as long as the ideas are entertaining, he's on board. And that is because, like most scientists and most popcorn-munching proto-scientists, he is curious and enthusiastic.

It is these very qualities that motivate both the science-fiction aficionado and the scientist, although the latter also needs patience, stamina and rigour. And that's why, for all their flaws (yes, the fact that the Hulk is larger than Dr Bruce Banner does violate the first law of thermodynamics), science-fiction films - good, bad or indifferent - are important.

Emma Marris is a retained correspondent at Nature.

\section{Dishing the dirt on hygiene}

\section{The Dirt on Clean: An Unsanitized History \\ by Katherine Ashenburg \\ North Point Press: 2007.368 pp. \$24 \\ Knopf Canada: 2007. 368 pp. Can\$35}

\section{Virginia Smith}

Nothing on cleanliness for 50 years and then two books come along at once - mine and Katherine Ashenburg's The Dirt on Clean. If anyone ever wanted to know about the biological, psychological, social and technical history of cleansing, it's all out there now. The history of hygiene is a new field that may yet influence public policy.

Ashenburg's neat distillation of historical anecdotes and graphic biographical details of personal hygiene is more focused on baths and bathing than on the principles of hygiene per se, in the mould set by Lawrence Wright's international best-seller Clean and Decent (1960). She does not attempt to cover medical therapeutics, natural philosophy, legislation, religion, sociology, grooming, or indeed anything before the Greeks. That gives her more space to investigate her key proposition: whether or not Europeans and Americans in the past were genuinely dirty and smelly.

She looks at bathing habits from the classical world to the twentieth century, borrowing at length from a wide range of letters, diaries and travel writings, combined with a good array of secondary historical sources. This approach allows the reader to relish all those salacious, deliciously taboo details of dirt, filth and personal body odour.

Ashenburg uses the psychology of dirt to provide insight into the later germ-inspired cleanliness crusade and the more recent, advertising-led campaign for personal hygiene. The fear of dirt is a psychological threshold that can be either raised or lowered, and Europeans were obviously fairly relaxed about it until the arrival of microbiological 'germs'. Even that fear faded during the past century - until the recent spate of antibacterial advertising. Ashenburg ends by addressing the fearful excesses of modern North American hygiene. These have become a burning issue in the light of the immunological theory relating hygiene to the soaring increase in child allergies in the Western world.

We are at the start of a long-overdue review

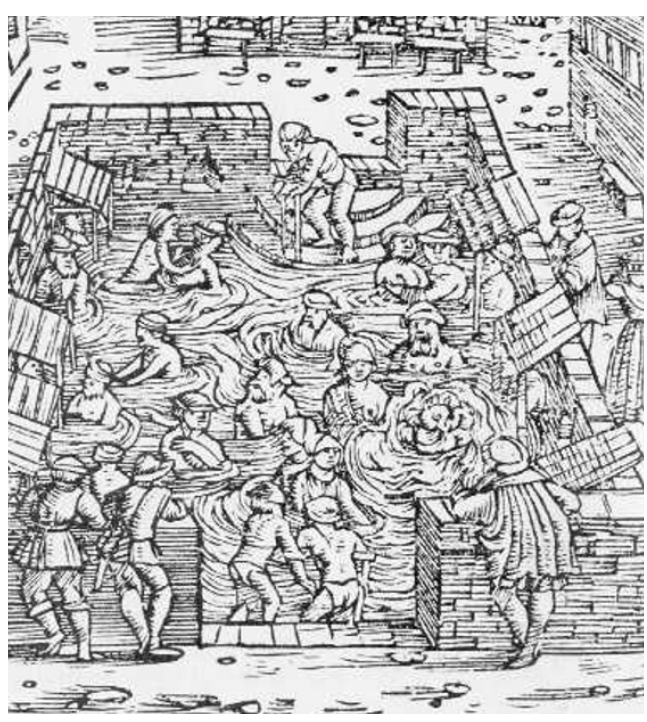

Fifteenth-century bathers in Baden, Switzerland, compromising their ablutions with decorative hats.

of nineteenth-century propaganda, which assumed (without much evidence) that a Dark Age of dirt began after the fall of Rome and was put right only by modern sanitation. Demographers and epidemiologists may still think that this was the case, but historians have been digging up some colourful cultural details that smudge this neat picture. They have confirmed that classical and mediaeval Europeans liked to bathe, and that plague and syphilis closed the public bath houses and put people off all but the most essential ablutions for a while during the seventeenth century.

Bathing habits had to be relearned during the eighteenth and nineteenth centuries. It was the long modern economic boom that allowed most industrialized countries to renew their civic infrastructure with water supplies and indoor plumbing. As recently as 50 years ago, only one in ten French homes and just over half of British and US homes had a plumbed bathroom. These figures obscure the twentiethcentury divide between urban and rural living conditions: most urban homes had a bath or shower by the 1950s, whereas rural areas did not catch up for another 10 to 20 years.

There are other deep-rooted themes emerging from the new history of hygiene that Ashenburg's bathing history cannot take into account, namely politics and medicine. Hygiene was the political force behind the democrat and the religious dissenter. It has given us enlightened sanitarianism and much-valued civic amenities such as parks, libraries and swimming pools; it contributed to eugenics race theory and to the contemporary consumer-based, science-led 'green' politics of pollution and climate change.

The history of health education and the development of a 'health regimen' underpin today's ideas of healthy behaviour, now promoted by government risk-awareness legislation, food-and-exercise campaigns, and regulation of 'work-life balance'. Another underrated therapeutic theme is beauty care, also booming at the moment. Personal grooming turns out to be something that we brought with us from the Neolithic, and is a form of nurture that, arguably, we can ill dispense with. If, like chimps, we spent many hours a day grooming back then, small wonder we spend time on it still.

Virginia Smith is an honorary research fellow at the London School of Hygiene and Tropical Medicine, London N19 5JS. She is the author of Clean: A History of Personal Hygiene and Purity. 